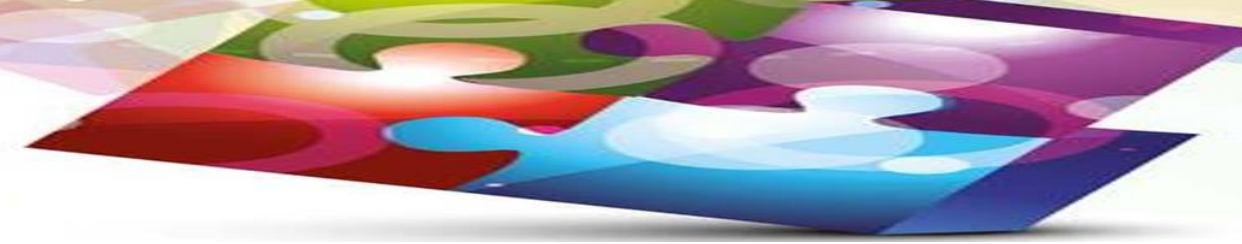

\title{
PERCURSOS PARA INSTITUCIONALIZAÇÃO DA EAD NO IFCE: A CONSTRUÇÃO DE UMA SISTÊMICA DE GESTÃO
}

\section{HOW TO SET UP DISTANCE LEARNING AT THE FEDERAL INSTITUTE IN CEARÁ: THE CONSTRUCTION OF A MANAGEMENT SYSTEM}

Régia Talina Silva ARAÚJO²

\begin{abstract}
Resumo: Nesse artigo relatamos como ocorreu a institucionalização da Educação a Distância (EAD) no Instituto Federal do Ceará enfatizando o modelo sistêmico de gestão. A partir dos editais da Universidade Aberta do Brasil e Escola Técnica Aberta do Brasil, percorremos a história da EAD na Instituição e como estruturamos um sistema de gestão. A metodologia teve por base os documentos legais internos e externos. Os resultados se evidenciam nos casos de sucesso, boas práticas, métodos, tecnologias, processos e produtos que englobam e integram a complexidade dos aspectos pedagógicos, tecnológicos, administrativo e financeiro, institucionais e diversidade de perfis dos profissionais envolvidos.
\end{abstract}

Palavras chaves: Educação a Distância - Institucionalização - Gestão da EAD.

ABSTRACT: This article reverberates and resumes how distance learning, and specifically its management system, were institutionalized at the Federal Institute of the Ceará. It is a report based on documentary records, the starting point being the nationwide public notice concerning the Open University of Brazil and Open Technical School of Brazil. The methodology used to elaborate this report was based on internal and external legal documents. The results are evidenced in successful cases, good practices, methods, process and products that encompass and integrate the complexity of pedagogical, technological, administrative, financial, and institutional aspects, and also the diversity of profiles of the professionals involved in creation.

Keywords: Distance Education - Institutionalization - Distance Learning Management

\section{Introdução}

No princípio era o verbo! Tecnologia! as primeiras experiências em EAD no Instituto Federal de Educação Ciência e Tecnologia (IFCE) tiveram origem em um projeto denominado INVENTE (SOARES, 2001), um sistema Web baseado em instrução que foi desenvolvido pautado não apenas com base na visão tecnológica, mas também levando em consideração

\footnotetext{
${ }^{1}$ Instituto Federal de Educação, Ciência e Tecnologia do Ceará (IFCE) projetos.cassandra@gmail.com

2 Instituto Federal de Educação, Ciência e Tecnologia do Ceará (IFCE) talinaregia@gmail.com
} 


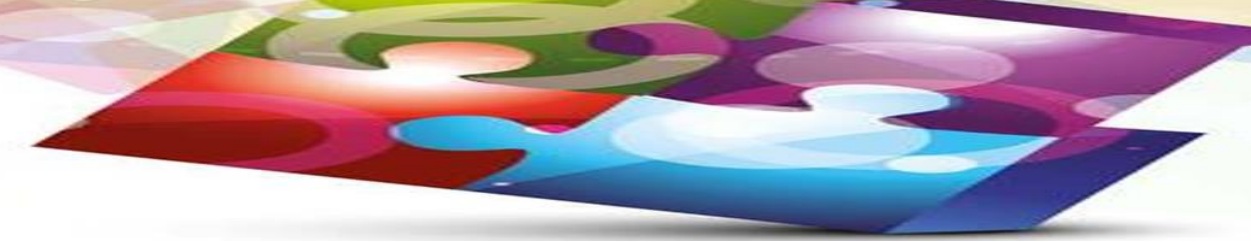

dimensões críticas do e-learning, tais como: "adaptação cultural”, "flexibilidade ambiental" e "exploração dos sentidos".

A ênfase do projeto INVENTE era desenvolver um produto tecnológico que atendesse à demanda de ensino-aprendizagem de cursos tecnológicos para oferta a distância atentos às suas especificidades. Resultou em diversos artigos, dissertações e teses e, atualmente, ganhou outras vertentes de pesquisa e desenvolvimento, tais como Re-invente (OLIVEIRA et al., 2003) e Big-invente (OLIVEIRA et al, 2015).

Por ocasião de um projeto financiado pelo Programa de Expansão da Educação Profissional (PROEP), em 2003³ ${ }^{3}$ denominado Ciranda da Educação profissional (2003-2006), do qual o IFCE participou, já se percebia a necessidade de compartilhar cursos e disciplinas interinstitucionalmente na Rede de Educação Profissional. Esse projeto contemplava oficinas sobre Didática da EAD em videoconferência e Informática Educativa e Jornadas Científicas. Assim, o primeiro modelo de EAD adotado na instituição foi por videoconferência dedicada. E ali começou-se a discutir a didática e a pedagogia de aulas em locais remotos.

A partir daí, a Instituição foi se preparando e criando cultura até o outro marco, que foi o Inter-Red (Projeto de Interoperação de Rede Virtual Telemática) ${ }^{4}$. Nesse processo, o IFCE coordenou a criação de NTEADs (Núcleos de Tecnologias e Educação a Distância) com os parceiros da rede de educação profissional e tecnológica para se prepararem para o E-Tec Brasil, o Edital da UAB (BRASIL, 2005a) já tinha sido lançado - e apenas 4 Institutos Federais (IFs), à época, denominados CEFET, tinham sido contemplados. A Secretaria de Educação Profissional e Tecnológica do Ministério da Educação (Setec/MEC), quando lançou o sistema E-Tec Brasil, abriu oportunidade para toda rede profissional aderir ao sistema, porém as instituições precisariam se preparar pedagogicamente, tecnologicamente e organizacionalmente (essa é uma boa história a ser contada a posteriori).

Pois bem, O IFCE foi uma das instituições da rede federal de educação profissional e tecnológica que teve aprovados dois cursos superiores pela UAB (BRASIL, 2005a): Hotelaria e Licenciatura em Matemática. E aqui começa nossa história para institucionalizar, construir e

\footnotetext{
3 Programa criado pelo MEC (Ministério da Educação) que buscou desenvolver ações integradas da educação com o trabalho, a ciência e a tecnologia, com o objetivo de implantar um novo modelo de Educação Profissional (MENEZES e SANTOS, 2001).

${ }^{4}$ Projeto desenvolvido pelo IFCE financiado e chancelado pelo MEC/SEED/SETEC. Tinha como objetivo implantar um sistema de compartilhamento, busca e recuperação de conteúdos digitais, com ênfase na educação profissional e tecnológica (SERRA et al., 2008).
} 
consolidar uma estrutura de gestão sistêmica para essa modalidade. Apresentamos neste artigo o cenário nacional propício à consolidação da EAD no IFCE, contamos um pouco da construção histórica da EAD na instituição, enfatizamos como organizamos a sistêmica de gestão de todos os subsistemas que a EAD Institucional comporta: o institucional, o pedagógico, o tecnológico, o administrativo-financeiro e os recursos humanos.

\section{O cenário nacional da EAD: Um salto para IPES - UAB e E-Tec Brasil}

O Decreto $\mathrm{n}^{\mathrm{o}}$. 5.622, de 19 de dezembro de 2005 (BRASIL, 2005b), regulamentou o Artigo 80 da Lei de Diretrizes e Bases n 9.394/96, estabelecendo as regras da modalidade e definindo EAD como a "modalidade educacional na qual a mediação didático-pedagógica nos processos de ensino e aprendizagem ocorre com a utilização de meios e tecnologias de informação e comunicação, com estudantes e professores desenvolvendo atividades educativas em lugares ou tempos diversos".

Ressalte-se que vige atualmente o Decreto no 9.057, de 25 de maio de 2017 (BRASIL, 2017), que atualiza o Decreto $n^{0} 5.622$ sobretudo em relação à flexibilização e à criação de cursos de EAD, permitindo a criação de polos de EaD pelas próprias instituições e o credenciamento de instituições na modalidade $\mathrm{EaD}$ sem exigir o credenciamento prévio para a oferta presencial. Entretanto, o processo de institucionalizaçcão aqui relatado deu início com o Decreto $\mathrm{n}^{\circ} 5.622$ e suas narrativas.

A partir da regulamentação da $\mathrm{EaD}$ e da Portaria n n $^{\circ} .059$, de 10 de dezembro de 2004 (BRASIL, 2004), as instituições de ensino superior (IES) puderam introduzir, na organização pedagógica e curricular de seus cursos superiores reconhecidos, a oferta de disciplinas integrantes do currículo que utilizem modalidade semipresencial. Essas disciplinas poderiam ser ofertadas integral ou parcialmente, porém a oferta não podia ultrapassar $20 \%$ da carga horária total do curso - determinação revogada pela Portaria n ${ }^{\circ} 1.134$, de 10 de outubro de 2016 (BRASIL, 2016) - com nova redação, que amplia a oferta para a modalidade a distância e abrange as instituições superiores com pelo menos um curso reconhecido.

Segundo os dados do Censo de Educação Superior de 2017 (BRASIL, 2018a) houve um crescimento exponencial no número de matrícula em cursos de graduação na modalidade a distância no período de 2007-2017 em instituições de ensino superior públicas (IPES) e privadas. Ressalte-se que, em 2007, havia apenas 369.766 alunos matriculados nessa 


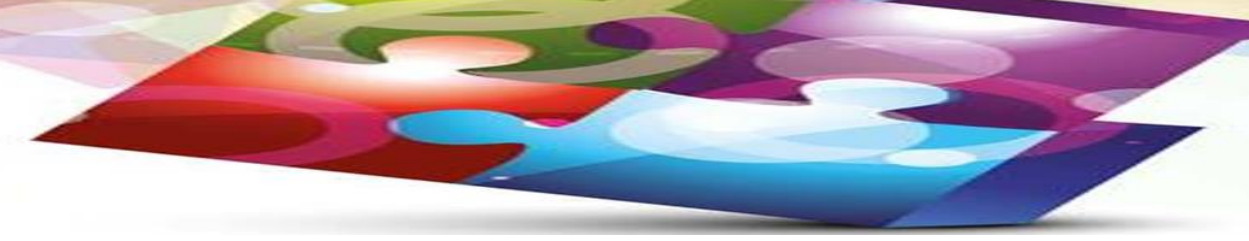

modalidade, representando 7\% de 5.250.147 estudantes no Brasil. Já em 2017, o número de matriculados na modalidade a distância foi de 1.765 .982 estudantes, representando $21,2 \%$ do total de 8.316.663 estudantes nas duas modalidades, presencial e a distância.

Nas IPES, esse crescimento foi impulsionado a partir de 2005, quando foi criado, pelo Ministério da Educação, o Sistema UAB (Universidade Aberta do Brasil), que tinha como foco o desenvolvimento de políticas e gestão da educação superior, com vistas à expansão de educação superior, no âmbito do Plano de Desenvolvimento da Educação - PDE. A UAB é então, um sistema integrado por instituições públicas de ensino superior (IPES) que ofertam cursos superiores na modalidade a distância e tem como apoio as unidades operacionais para desenvolvimento descentralizado de atividades pedagógicas e administrativas relativas ao cursos e programas ofertados a distância pela IPES, também chamados de polos de apoio presencial. Segundo o portal da UAB/CAPES, de 2007 a julho de 2009, foram aprovados e instalados 557 polos de apoio presencial com 187.154 vagas criadas nas diversas regiões que compõem nosso país.

Contribuindo ainda com o crescimento e a democratização do ensino superior público e de qualidade, em 2009 o sistema UAB selecionou mais 163 novos polos, no âmbito do Plano de Ações Articuladas - PAR, para equacionar a demanda e a oferta de formação de professores na rede pública da educação básica, ampliando a rede para um total de 720 polos (GOMES, 2013; SANTOS, 2016).

Já em 2010, o Sistema UAB previa o estabelecimento de 1.000 polos estrategicamente distribuídos no território nacional. Segundo dados extraídos do SisUAB que é a plataforma de suporte para execução, acompanhamento e gestão do processo da Universidade Aberta do Brasil, existiam 118 instituições credenciadas para oferta em EaD, entre Universidades Federais, Universidades Estaduais e Institutos Federais de Educação, Ciência e Tecnologia (IFs) e 948 polos distribuídos no território nacional, estando próximo de atingir a meta dos 1000 polos. Apesar do aumento no número de matrículas de graduação no país na modalidade a distância de 2007-2017, registra-se em 2014 uma diminuição de ingressos de estudantes via sistema UAB. Segundo relatório de gestão de 2017 da CAPES (BRASIL, 2018b), havia a previsão de matrícula de parte dos 194 mil alunos aprovados no âmbito do Edital 75/2014. Entretanto, devido a restrições orçamentárias, a admissão de novos alunos não pôde ser concretizada naquele exercício. Já em 2016/2017, houve aporte de novos recursos, e o ingresso 
dos alunos provenientes do referido edital foi efetivado, ampliando novamente a base atendida pela UAB.

Em nível de ensino técnico estimulando o crescimento da modalidade a distância em instituições públicas, tem-se como iniciativa do governo federal o Edital $\mathrm{n}^{\circ}$ 01/2007/SEED/SETEC/MEC da Escola Técnica Aberta do Brasil que buscava democratizar o acesso a cursos técnicos de nível médio, públicos e gratuitos no país.

O e-Tec Brasil foi consolidado pelo governo federal em 2008, inicialmente com 48 cursos a distância gratuitos, com 193 polos de apoio presenciais em universidades e escolas, atendendo a, aproximadamente, 23 mil alunos. Em 2010, o número de polos chegou a 259 e cerca de 29 mil alunos atendidos. Em 2011, foram matriculados cerca de 23 mil alunos distribuídos no território nacional. A partir de 2015, houve uma diminuição no número de matrículas. Como mostram os gráficos da Figura 1, que ilustram os números de matrículas e polos implantados em nível nacional do e-Tec Brasil, extraído do Sistec ${ }^{5}$, o sistema nacional de informações da educação profissional e tecnológica no período de 2008 a 2016.

Figura 1. Matrículas e polos implantados na Rede e-Tec Brasil de 2008 a 2016.

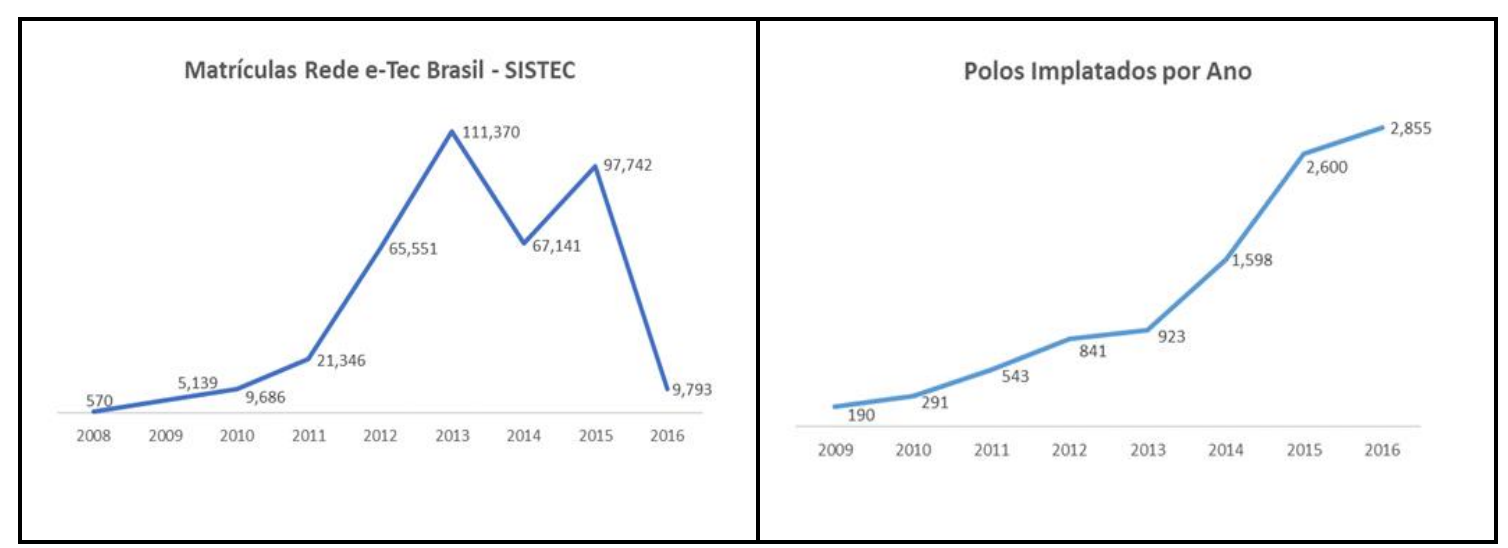

Fonte: Sistec (2016).

Assim, quer seja como política pública de consolidação, os programas nacionais de ensino superior e formação técnica na modalidade a distância, como a UAB e o E-tec Brasil, criados em 2005 e 2007, respectivamente, pelo Ministério da Educação (MEC), vêm favorecendo significativamente a expansão e a interiorização do ensino superior, técnico e de pós-graduação no país.

\footnotetext{
${ }^{5}$ https://sistec.mec.gov.br
} 
Além dos programas e dos sistemas incentivados pelo governo federal, tem-se o impulso proporcionado pela Portaria $n^{\circ}$ 4.059/2004 num esforço de articulação e de integração (até a fusão) das modalidades de ensino presencial e a distância.

Ressalte-se ainda que a Educação a distância, baseada em seus pressupostos teóricometodológicos e fortalecida pela exigência da legislação nacional vigente, apresenta complexidades e especificidades próprias dessa modalidade de ensino, pois envolve multidisciplinaridades, processos e produtos, tecnologias e metodologias apropriadas e moldadas àquele fim.

\section{Origem, implantação e consolidação da EAD no IFCE}

Em acordo com o cenário brasileiro, o IFCE acompanhou o crescimento da EAD, e se antecipou a ele, pois vem realizando pesquisas e experimentação em EAD desde 1994. A exemplo desse fato, destaque-se o projeto INVENTE (SOARES, 2011). A partir daí, diversas ações foram realizadas no âmbito do ensino, da pesquisa e da extensão como se resume a seguir.

No ensino, pode-se citar um programa denominado FormaTE (Formação em Tecnologia Educativa) realizado nos anos de 2003 e 2004, que se constituiu de minicursos diversos de formação e capacitação de professores em tecnologias informáticas telemáticas e EAD visando à alfabetização tecnológica, utilização de TICs em sala de aula, conhecimento e domínio de ferramentas e plataformas de EAD e produção de conteúdo. Os minicursos foram decorrências necessárias do projeto piloto "Ciranda da Educação Profissional”, realizado entre quatro IFCEs usando videoconferência dentro do Programa de Expansão da Educação Profissional - PROEP. Igualmente, nessa ocasião, foram preparados e realizados cursos de Didática Aplicada à Videoconferência para professores do IFCE, repetido em diversas ocasiões, capacitação no e-PROINFO e capacitação em EAD.

Em 2005, por ocasião do desenvolvimento do Projeto Inter-Red que tinha como objetivo a construção colaborativa de um repositório de conteúdos digitais da Rede de Educação profissional (SERRA et al., 2008) foram institucionalizados, além do IFCE - Portaria $n^{\circ}$ 234/GDG, de 14 de junho de 2006, a criação dos Núcleos de Tecnologias Educacionais e Educação a Distância - NTEADs, via portarias, nos seguintes IF: ETF Palmas, CEFETPE, CEFETRR, CEFETRN, CEFETPB, CEFETCampos-RJ, CEFETSC, EAF de Cáceres, que 


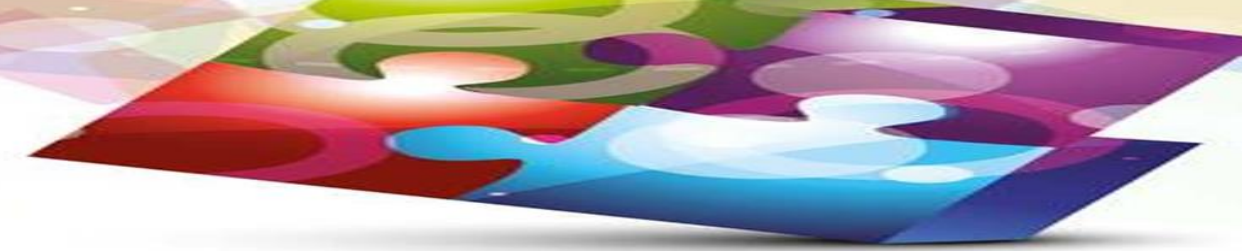

participavam da fase experimental do projeto, já com vistas a implantar ofertas em Educação a Distância. Inicialmente o Projeto contemplava oito IF da Rede Norte e Nordeste de Educação Tecnológica-REDENET, ampliando-se para os demais CEFET. O Inter-Red, evoluiu para um Portal Nacional denominado EPCT Virtual (SERRA et al., 2008), com outras ferramentas, com o IFCE à frente da concepção, desenvolvimento e gestão do projeto.

Ainda, em 2005, o IFCE (à época CEFETCE) apresentou proposta para ofertar cursos na modalidade a distância, balizados pelo Edital 1 de 16/12/2005 SEED/MEC (publicação no DOU, seção 3, pág. 39-41) via Universidade Aberta do Brasil, em que foram contemplados dois cursos superiores, a saber, Licenciatura em Matemática e Tecnologia em Hotelaria (à época chamado de Tecnologia em Hospedagem). Assim, em 2007, esses dois cursos tiveram a aprovação para implementação pela Portaria n 111/GDG de 21 de março de 2007.

A consolidação da Universidade Aberta do Brasil no IFCE em 2007 ocorreu com a oferta dos cursos acima citados em polos de apoio presencial no interior do estado, possibilitando o acesso a 400 alunos ingressarem no IFCE na modalidade de ensino a distância. Para atender essa demanda, foi institucionalizado um Núcleo de EAD, o NTEaD pela portaria 234/GDG de 14 de junho de 2006. Os NTEaD foram criados dentro das instituições publicas de ensino superior (IPES) como parte integrante do protocolo de candidatura da instituição à adesão ao sistema UAB (AMIEL et al., 2017).

Posteriormente o NTEAD do IFCE evoluiu para uma Diretoria sistêmica denominada DEaD, que foi criada pela portaria n ${ }^{\circ}$ 318/GDG, de 13 de março de 2009. O NTEAD já abrigava projetos e programas de TIC na Instituição, porém reformulou-se para abrigar a gestão e a produção dos cursos a distância da UAB. Daí o desenvolvimento de uma sistêmica de gestão, infraestrutura e formação de equipe multidisciplinar de preparação e de implementação dos cursos.

Os cursos de Licenciatura em Matemática e Tecnologia em Hotelaria (evoluiu do curso de tecnologia em Hospedagem) na modalidade a distância no IFCE possibilitaram, em 2008, o ingresso de 553 alunos e, em 2009, de 382 alunos distribuídos em 13 municípios do interior do estado do Ceará. Em 2010, o número de ingresso foi de 442 para os dois cursos superiores. Em 2011, houve ingresso de apenas 5 alunos no curso de Hotelaria, por transferência de polo. Em 2012 o número de ingresso foi de 174 estudantes direcionadas ao curso de Licenciatura em 


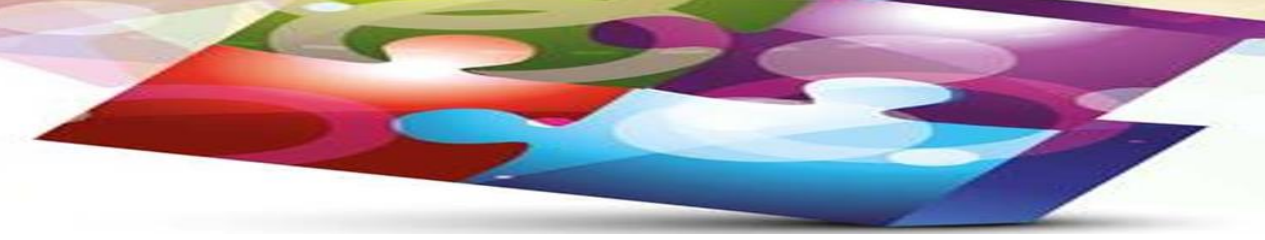

Matemática. Esse fato se deveu a mudanças nas regras para reofertas de cursos via UAB, informado via ofício circular no 09/2011-DED/CAPES, no qual informou as IPES que participavam do sistema UAB a não possibilidade de fomento em 2012 para cursos de bacharelado, dando prioridade a cursos voltados para formação de professores. O IFCE recorreu ao Ofício Circular n ${ }^{\circ}$ 09/2011, demonstrando as justificativas de excepcionalidade do curso de Hotelaria para o estado do Ceará porque, além de ser polo turístico, haveria os preparativos para Copa do Mundo de 2014, entre outros investimentos já realizados, no que foi posteriormente atendido e, consequentemente, reativadas as reofertas.

Em 23/09/2011, via portaria do MEC n 1328, foi instituída a Rede Nacional de Formação Continuada dos Profissionais do Magistério da Educação Básica. Com o objetivo de colaborar com a política pública do governo em 2012, foi criado o Curso Superior de Licenciatura em Educação Profissional, Científica e Tecnológica, constituindo-se uma oportunidade para a formação e a qualificação de professores em diferentes municípios do Ceará, carentes e distantes dos centros formadores. O PPC do curso EPCT foi aprovado por $a d$ referendum do Conselho Superior do IFCE via resolução no 041, de 9 de agosto de 2013.

Assim, em 2013, o IFCE possibilitou o ingresso de 105 estudantes para o curso de EPCT na modalidade a distância via UAB. Além disso, houve mais 549 alunos distribuídos nos cursos de Licenciatura em Matemática e Hotelaria, totalizando 654 matriculados neste ano. Em 2014 não houve oferta, porém, em 2015, 286 estudantes ingressaram nesses cursos, sendo 105 em EPCT, 86 em Hotelaria e 95 em Licenciatura em Matemática.

A Figura 2 resume os dados relacionados ao ingresso dos estudantes nos três cursos superiores ofertados na modalidade a distância via Universidade Aberta do Brasil no período de 2007 a 2015, totalizando 2.896 matrículas realizadas no IFCE. Os dados foram extraídos do sistema de controle acadêmico do IFCE, consultado em setembro de 2019, cedidos pela Coordenação de Controle Acadêmico - CCA - do IFCE - Campus Juazeiro do Norte e Campus Fortaleza. Esses alunos estavam distribuídos em 13 municípios no interior do estado do Ceará, nos quais possuíam polos de apoio presencial para apoiar as atividades didáticas dos respectivos cursos. Em consonância com o que foi relatado na seção 2, em relação ao número de estudantes ingressantes via sistema UAB, a partir de 2014, houve uma diminuição da oferta de vagas no IFCE. 


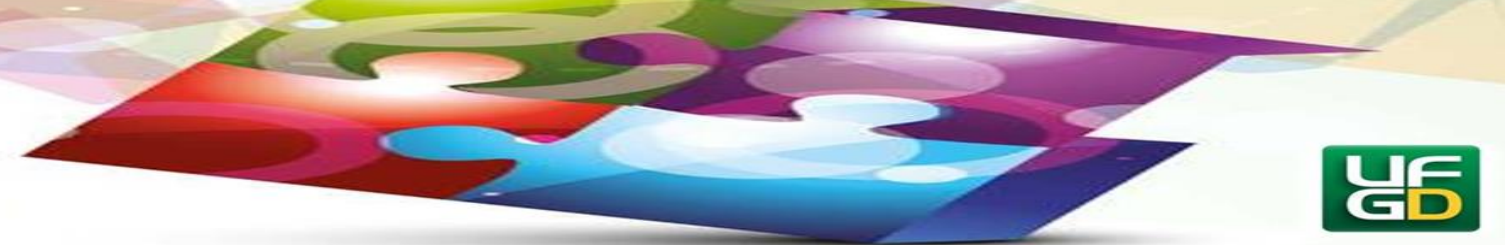

Figura 2. Número de matrículas dos cursos de graduação EAD do IFCE - Período 2007 - 2015

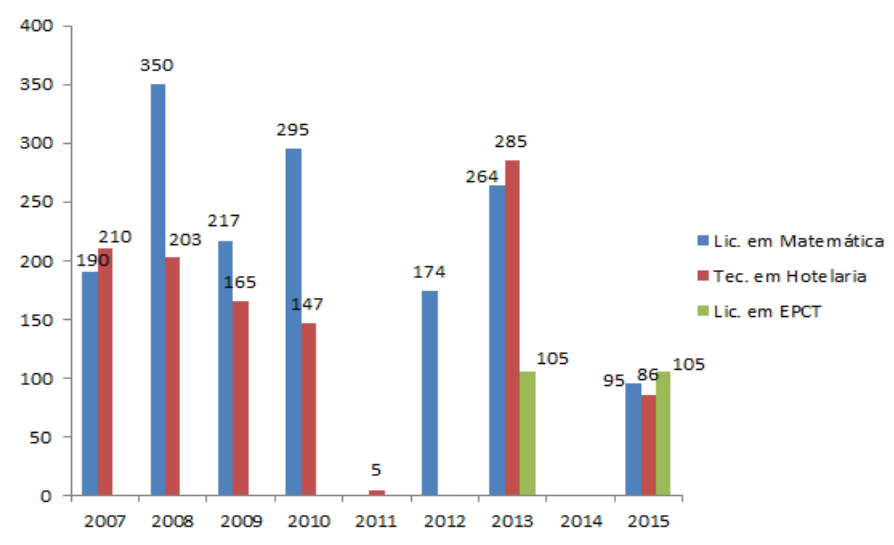

Fonte: CCA- IFCE (2019)

Ainda em relação ao ensino, porém, agora tratando do ensino técnico. Em 2007, O IFCE implementou o sistema Escola Técnica Aberta do Brasil - e-Tec Brasil, ofertando cursos, tais como Edificações, Eletrotécnica, Informática, Segurança do Trabalho e Redes de Computadores. Esses cursos foram contemplados via programa e-Tec através do Edital 01/2007/SEED/SETEC/MEC. Esse programa estava inserido no âmbito da política de expansão da educação profissionalizante e se constituía como uma das ações do Plano de Desenvolvimento da Educação- PDE. Tratou-se, pois, de um passo importante para a democratização do acesso ao ensino técnico público, através da modalidade de educação a distância. O número de matriculados no IFCE nesses cursos técnicos via e-Tec Brasil até 2014 foi de 3.476. Sendo que foram realizadas 539 matrículas em Edificações, 794 em Eletrotécnica, 1008 em Informática, 846 em Segurança do Trabalho e 289 em Redes de Computadores.

Posteriormente, o Sistema e-Tec Brasil em 2011 foi substituído pela Rede e-Tec ${ }^{6}$, criada pelo Ministério da Educação via Decreto ${ }^{\circ} 7.589 / 2011$. O objetivo da política de ensino técnico a distância era ampliar a oferta da EPT no País, de forma a atingir as metas 10 e 11 estabelecidas pelo PNE 2014-2024. Assim, a Rede e-Tec foi revista e ampliada em 2015.

Registra-se também, em 2012, uma parceria entre MEC-SEDUC-IFCE para oferta de cursos técnicos do Profuncionário (Programa de Formação Inicial em Serviço dos Profissionais da Educação Básica dos Sistemas de Ensino Público) via Rede e-Tec Brasil. O Profuncionário foi uma iniciativa do governo federal para ofertar formação técnica a distância

\footnotetext{
${ }^{6}$ http://portal.mec.gov.br/rede-e-tec-brasil
} 


\section{HORIZONTES - REVISTA DE EDUCACÃO}

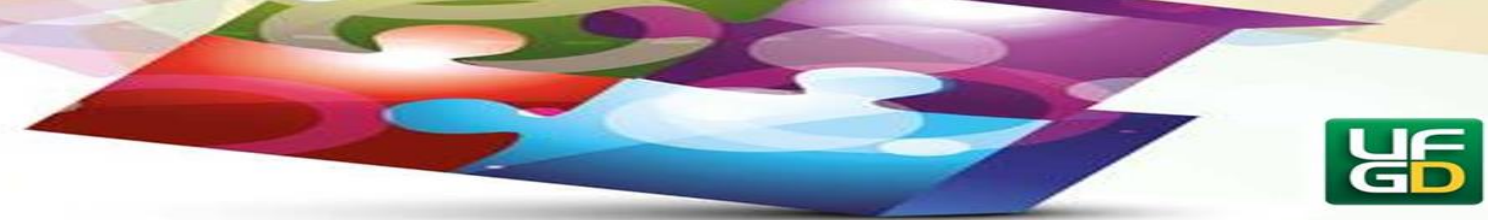

para profissionais da Educação Básica dos Sistemas de Ensino Público do país. Foram matriculados no IFCE 2.798 profissionais, distribuídos em 17 municípios do Ceará nos cursos técnicos em a) Infraestrutura Escolar (259); Alimentação Escolar (399); Secretaria Escolar (1723) e Multimeios Didáticos (417), totalizando 2.798 matrículas. A Figura 3 ilustra o quantitativo de matrículas de cursos técnicos do IFCE ofertados na modalidade a distância no período de 2007 - 2014.

Figura 3. Número de matrículas dos cursos técnicos - EaD do IFCE - Período 2007 - 2015

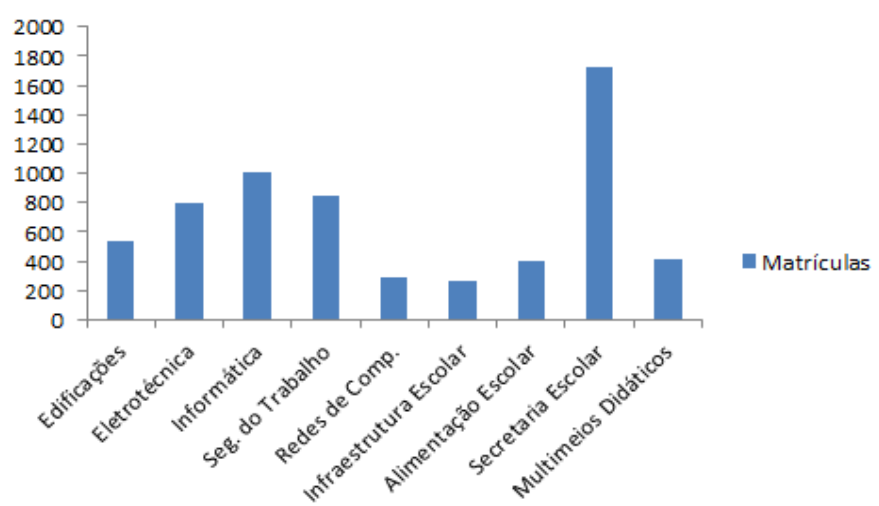

Fonte: CCA- IFCE (2018)

Inclui-se ainda em relação ao ensino os cursos de pós-graduação lato sensu de Educação Ambiental, Educação de Jovens e adultos e Produção de Material Didático, todos com ênfase na diversidade. Em 2010, foram ofertadas 300 vagas. Além disso, em 2013, foi ofertado o curso de especialização em Turismo e Hotelaria, com 94 vagas e em Educação Profissional e Tecnológica - EPCT, com 511 vagas. Já em 2014, foram ofertadas 200 vagas para o Curso de Especialização em Elaboração e Gerenciamento de Projetos para a Gestão Municipal de Recursos Hídricos, na modalidade a distância, em Parceria com a Agência Nacional de Águas (ANA). Totalizando assim, 1.115 vagas ofertadas em cursos de pósgraduação lato sensu na modalidade a distância.

No Quadro 1, está o resumo do quantitativo de vagas dos cursos implementados pelo IFCE na modalidade a distância em níveis técnico, graduação e especialização no período de 2007 a 2015. 
Quadro 1. Quantitativo de matrículas/vagas nos cursos ofertados pelo IFCE na modalidade a distância no período de 2007-2015.

\begin{tabular}{|l|l|}
\hline \multicolumn{1}{|c|}{ Níveis } & \multicolumn{1}{|c|}{ Quantitativo de Matrícula / Vagas } \\
\hline Técnico & 6.274 \\
\hline Graduação & 2.896 \\
\hline Pós- Graduação (Especializações) & 1.115 \\
\hline Total & 10.285 \\
\hline
\end{tabular}

Fonte: CCA- IFCE (2018)

Nesse contexto de produção e oferta, a Diretoria de Educação a Distância (DEaD) do IFCE já estava em pleno funcionamento vinculada no organograma institucional à Pró-reitoria de Ensino. A DEaD nasceu com o objetivo de implementar, acompanhar e avaliar políticas, projetos e programas institucionais atinentes às modalidades de ensino a distância, presencial e semipresencial, a partir do emprego de tecnologias digitais, incluindo as condições didáticopedagógicas, administrativas e tecnológicas necessárias ao seu bom funcionamento que contemplasse as especificidades e especializações dessa modalidade de ensino. O desenho do modelo de gestão empregado nessa diretoria será descrito no item seguinte, bem como são apresentados argumentos que comprovam a necessidade de se regulamentar e criar uma estrutura organizacional para a Educação a Distância na forma de Campus Sistêmico.

No planejamento estratégico traçado para DEaD (2009-2013) foi definida a missão $\mathrm{DEaD}$ que estava pautada no fornecimento de serviços e de produtos voltados à área de Ensino a Distância, semipresencial e presencial, promovendo o acesso e a democratização do conhecimento de forma ética e humana, contribuindo para qualidade de ensino, pesquisa e extensão com colaboradores e parceiros qualificados e comprometidos. Perseguia, como visão, consolidar-se como referência de Educação a Distância no país até 2013. A visão e a missão foram consolidadas e cumpridas, na medida em que o IFCE aumentou o número vagas na oferta da modalidade a distância e foi contemplado com vários projetos em nível nacional sob sua responsabilidade. Ressalte-se que iniciamos com a oferta de dois cursos de graduação em 2007 atendendo 4 polos e 400 vagas e, atualmente, o IFCE oferta cursos nível técnico, graduação, pós-graduação (Quadro 1) em mais de 20 polos no estado do Ceará e essa oferta é ampliada para outras regiões do país, atendendo a, aproximadamente, 10.285 pessoas. Os valores bem 


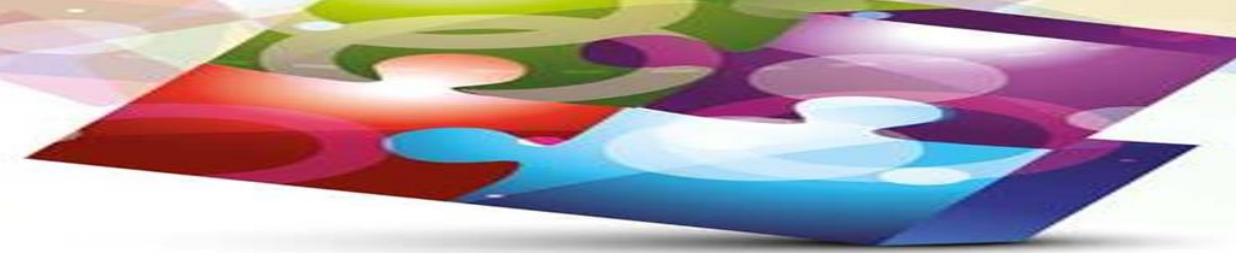

incorporados pelas equipes dos subsistemas de gestão eram ética, comprometimento, qualidade, humanidade, inovação, trabalho em equipe e valorização dos colaboradores e parceiros.

\section{O Sistema de gestão da DEaD}

Já consolidada como Diretoria de Educação a Distância, a partir da Portaria no 318/GDG de 13 de Março de 2009 e considerando toda a complexidade e as especificidades da modalidade de EAD que vinha sendo construída, a instituição, sua gestão e captação de recursos oriundo dos editais programas investiu em infraestrutura e em formação de equipe multidisciplinar, bem como criou-se uma sistêmica de gestão baseada em literatura existente, que mais se encaixava para atender aos cursos ofertados na modalidade a distância nos níveis superior, técnico, pós-graduação, além da pesquisa e da extensão. Um Programa de Educação a Distância (EAD) requer um trabalho detalhado que se desdobra em inúmeras tarefas de acordo com suas particularidades. As demandas são de toda ordem, e as soluções únicas, muitas vezes não funcionam em fatos novos.

Estabelecer um modelo de gestão está intrinsicamente ligado a institucionalização da EAD, pois segundo Ferreira e Carneiro (2015) a institucionalização da EAD pode ser descrita como um fenômeno relacionado ao alinhamento e à organização sistêmica dessa modalidade, com o objetivo de tornar as políticas de EAD sustentáveis e qualitativamente equivalentes ao ensino presencial.

Transpondo para instituição pública de ensino, a gestão da EAD adquire alto grau de complexidade, pois, para implantar e manter os cursos, é necessário um conjunto de processos (e produtos) que se integram, se articulam e se influenciam mutuamente visando o alcance de metas pré-definidas e planejadas. Para isso há divisão dos trabalhos, atribuições de responsabilidades a pessoas, prazos, recursos materiais e tecnologias, processos, resultados, definição de níveis de autoridades e estabelecimento de mecanismos de comunicação, sendo este o principal instrumento de coordenação.

Vale ressaltar que Educação a Distância se faz com o trabalho articulado de uma equipe multidisciplinar e exige múltiplas especialidades, competências e papéis, sobretudo para a produção de material didático, cerne da EAD, objeto de toda mediação pedagógica. Diferente do modelo presencial, o tempo de ensinar (produção e gestão pedagógica) é diferente do tempo 
de aprender (em qualquer lugar, em qualquer horário), Daí, a necessidade do planejamento, produção de materiais e recursos serem executados antes dos cronogramas de oferta de disciplinas e cursos. Como exemplo, algumas das funções e das competências de uma equipe multidisciplinar para atender as especificidades da EAD, tanto técnica como pedagógica, são administrar o ambiente virtual de aprendizagem (AVA), produzir vídeos, diagramar materiais didáticos web e impresso, revisar, ilustrar e animar materiais, programar e desenvolver ferramentas, criar e acompanhar o desenvolvimento do modelo instrucional de curso/disciplina, fazer mediações e acompanhar o desenvolvimento dos estudantes, elaborar material didático, entre outras funções.

Por isso o modelo mais adequado que elegemos para nortear a gestão da $\mathrm{DEaD}$, feitas pequenas modificações conceituais, foi o modelo de Gestão Sistêmica que trata da integração de todas as áreas de uma organização buscando assegurar o cumprimento de prazos, manutenção da qualidade e equilíbrio de ações de maneira a proporcionar diferencial educacional, garantindo continuidade e credibilidade e com visão de futuro.

Neste sentido, conhecer todos os aspectos de gestão em EaD foi essencial para que ela fosse desenvolvida com qualidade. O modelo construído compreende cinco grandes pilares, que são: institucional, pedagógico, tecnológico, administrativo-financeiro e recursos humanos, conforme ilustra a Figura 4. Todas as ações realizadas pela então Diretoria no âmbito do IFCE visam, institucionalmente, formas de fazer funcionar esse modelo e constituir fator de sucesso no sistema de educação a distância, bem como o aperfeiçoamento e consolidação de um modelo de gestão de sistemas de EAD. Esse modelo nos permitia acompanhar o andamento e os resultados de todos os processos de forma setorial e globalmente, pois nenhum dos subsistemas podia falhar sob pena de comprometer os resultados e prazos dos demais.

Figura 4. Gestão Sistêmica - IFCE

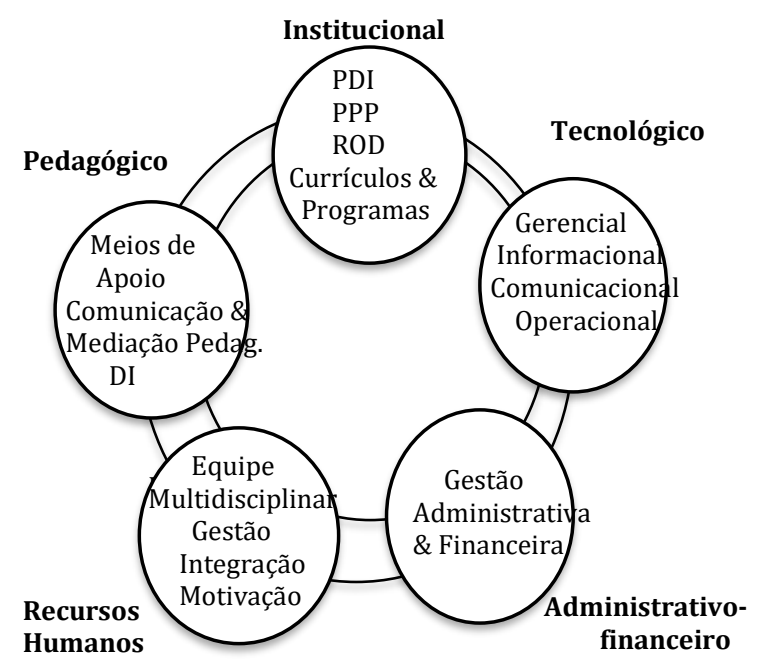




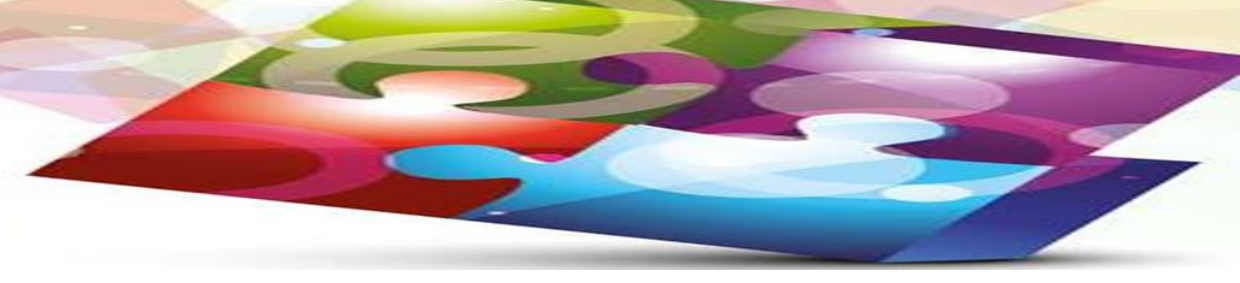

Na abordagem sistêmica da Educação a Distância no IFCE, o direcionamento é baseado nos conceitos e nas técnicas que integram um sistema de gestão empresarial com seus objetivos, partes componentes e requisitos para que sejam úteis na administração, segundo Arantes (1998).

Destaque-se que os componentes do sistema de gestão adotado, são constituídos por cinco subsistemas integrados e com forte interdependência. O primeiro, o Institucional, que reúne os instrumentos que auxiliam a administração a fixar a razão de ser da gestão educacional de acordo com as crenças, os valores, as convicções e as expectativas da Instituição. Define também a identidade da instituição, caracterizando as finalidades internas e externas que ela se propõe a atender.

Podemos citar, dentre os instrumentos, afora a macro legislação, o Plano de Desenvolvimento Institucional (PDI), que é o documento que identifica a Instituição de Ensino Superior (IES), no que diz respeito à filosofia de trabalho, à missão a que se propõe, as diretrizes pedagógicas que orientam suas ações, à sua estrutura organizacional e as atividades acadêmicas que desenvolve, ou mesmo, pretende desenvolver, podemos dizer que é o seu planejamento estratégico. O PDI é elaborado para um período de cinco anos. No interregno dessa gestão, participamos e consolidamos os objetivos estratégicos para a EAD, tais como a) desenvolver uma cultura institucional favorável à incorporação das tecnologias digitais ao ensinoaprendizagem nas diferentes modalidades e níveis de ensino; b) apoiar, acompanhar e controlar o uso das tecnologias digitais no ensino presencial dos cursos regulares, nos campi do IFCE; c) promover o acesso ao ensino técnico e superior a jovens e adultos, mediante programas de Educação a Distância (EaD); d) buscar a cooperação de instituições locais e estrangeiras, com o objetivo de desenvolver a educação a distância em parceria, dentre outros objetivos (PDI 2014-2018) ${ }^{7}$.

Araújo (2014) investigou o modelo de gestão de cursos aplicados na modalidade de educação à distância no Instituto Federal de Educação, Ciência e Tecnologia do Ceará - IFCE

\footnotetext{
${ }^{7}$ https://ifce.edu.br/instituto/documentos-institucionais/plano-de-desenvolvimento-institucional
} 


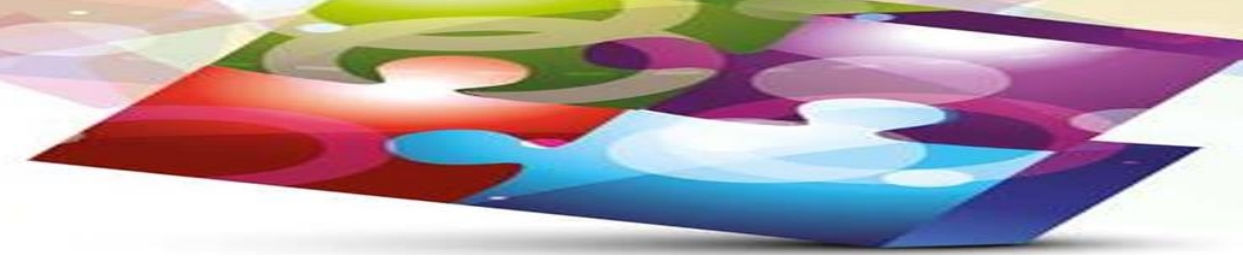

e constatou que o modelo de gestão da EaD adotado pelo IFCE está alinhado com o Plano de Desenvolvimento Institucional, demonstrando a intencionalidade de educar, validando e orientando as práticas de $\mathrm{EaD}$.

Outro instrumento de auxílio à gestão em EAD do Instituto é o Projeto Político Pedagógico (PPP), que vai desde os ressaltes da história institucional, de seus currículos, métodos e o conjunto de seus atores, corpos docente e discente, que contribuíram para a projeção nacional do Instituto Federal de Educação, Ciência e Tecnologia do Ceará, no que diz respeito à difusão e à qualidade do ensino.

Destacamos, ainda, o documento Termo de Acordo de Metas (TAM), SETEC/MEC, item 9, que trata da oferta de cursos a distância, no qual estabelece a "implantação da modalidade de Educação a Distância como atividade regular no Instituto Federal".

Outro susbsistema fundamental para a gestão em EAD é o tecnológico, que é constituído pelos instrumentos que dão suporte à administração e agem de forma catalisadora na obtenção de dados que auxiliam as tomadas de decisões para o alcance dos resultados institucionais, no que diz respeito à orientação, à organização, à coordenação e ao controle das atividades de Tecnologia da Informação, de forma a assegurar que elas sejam dirigidas às finalidades, agregando, ainda, valores importantes para a sustentabilidade do sistema de gestão em EaD, que engloba toda a infraestrutura tecnológica de serviços e de produtos, como AVA, mídias e materiais de suporte acadêmico, automatização de processos e desenvolvimento técnico e científico como os Learning Vectors (SALES, 2010), MADE (SANTIAGO, 2014), DIDATIC (BRAGA, 2008), AVALTIC (SILVA, 2008), que geraram teses, dissertações e artigos.

Em seguida, temos os Recursos Humanos, que contemplam um conjunto de colaboradores capacitados, em diversas áreas do conhecimento, que executam tarefas inerentes ao modelo de Educação a distância adotado pelo IFCE. Os colaboradores são recrutados e selecionados por competência, alinhados ao planejamento estratégico, e capacitados e lapidados, levando-se em consideração os fatores internos e externos à instituição, com uma visão de futuro, de forma que se busca a alocação de profissionais certos em posições estratégicas para garantir o cumprimento de metas a curto, médio e longo prazo. Para o auxílio no cumprimento dessas metas, utilizamos ações dirigidas à motivação, ao desenvolvimento da 
autonomia, ao trabalho em grupo e colaborativo, à integração da equipe e à valorização dos objetivos pessoais com os institucionais. Todos os colaboradores participavam de capacitações e de reuniões gerais de alinhamento com frequência regular: tutores, coordenadores, técnicos, designers, revisores, professores, programadores, diagramadores. Nessas reuniões, cada célula, gestão e produção, apresentava o andamento de suas atividades, bem como suas principais dificuldades para realizá-las.

O subsistema administrativo-financeiro é baseado nas leis que tratam da gestão orçamentária das instituições públicas, buscando, através de uma descentralização de recursos a uma fundação de apoio à pesquisa, que, dentro das normas exigidas pela lei, visa ao apoio à execução e à fiscalização dos gastos com as ações inerentes à Educação a Distância, para que se possa, de uma forma eficiente e eficaz, aliar custo e benefício para o alcance de metas e de objetivos pré-estabelecidos no planejamento estratégico institucional.

Araújo et al. (2015) implementaram a modelagem do processo de gestão administrativo-financeira do IFCE em redes de Petri coloridas e obtiveram como resultado a identificação e a melhora nas ações/atividades desenvolvidas nesse processo, permitindo uma visualização gráfica do fluxo do processo administrativo-financeiro, auxiliando, assim, a equipe do IFCE nas ações de planejamento e de execução dos recursos captados para oferta dos cursos na modalidade a distância.

O subsistema que compreende o setor Pedagógico, fundamental no modelo pedagógico e na filosofia da Rede EPCT no desenvolvimento das nossas ações em EAD, no desenho instrucional e gestão do ensino e aprendizagem provida, está pautado na perspectiva dada por Le Boterf et al. (1992), que trata da questão da gestão da oferta e da qualidade da formação. O foco da abordagem é no "cliente", que, no caso de uma instituição de ensino, é o aluno. O olhar pedagógico orienta e contribui com um conjunto coerente de escolhas de pontos de vista, de orientações metodológicas, de representações, de conceitos, de transposição didática de materiais e de princípios de ações que definem o ângulo da abordagem centrada no cliente (aluno), tornando-se, assim, o fio condutor de uma gestão da qualidade. Isso tudo se concretiza nos planos pedagógicos, no desenvolvimento e na aplicação do design educacional. No detalhe do modelo pedagógico implementado dos cursos, aprimoramos e adequamos um modelo do IFCE em Guedes (2011) e procedemos a estudos relativos a seus impactos em Schmidlin (2013), Mineiro (2011), Moreira (2014), Rodrigues (2015) e Araújo (2015). A 


\section{HORIZONTES - REVISTA DE EDUCACÃO}

condição de adequar a abordagem de conhecimentos de uma forma que busque prender a atenção do aluno, oferecendo a ele a condição de estudar e de desenvolver sua autonomia, através de recursos incorporados aos materiais impresso e digital, faz desse pilar pedagógico um excelente diferencial e um terreno fértil para a obtenção dos objetivos propostos pelo IFCE. A Figura 4 busca apresentar como se articulam esses subsistemas.

Com todo esse escopo, projetamos e recomendamos, como proposta institucional, a criação de um Campus $\mathrm{EaD}$, tendo, pois, como função estratégica, prover e articular as políticas, os processos, a gestão e a produção de material didático voltadas para o ensino a distância. O Campus EaD trabalhará com os NTEADs (Nucleos de Tecnologias Educacionais e Educação a Distância) de forma descentralizada e compartilhada. Os NTEADs, por sua vez, estão ou serão instalados nos diversos campi do $\mathrm{IFCE}^{8}$, atualmente são 35 , através de portaria e terão como principal função executar as ofertas dos cursos propostas por cada Campus, com seus respectivos Polos de Apoio Presencial. Na Figura 5 é mostrado o modelo sistêmico da proposta Campus EaD com os NTEADs e polos de apoio presencial.

Ressalte-se que já estão institucionalizados os campi de Fortaleza, Juazeiro do Norte, Maracanaú, Quixadá e Iguatu por Portaria de suas Diretorias Gerais. A meta é atender a todos os campi com oferta de cursos.

Figura 5: Modelo Sistêmico do Campus EaD - IFCE

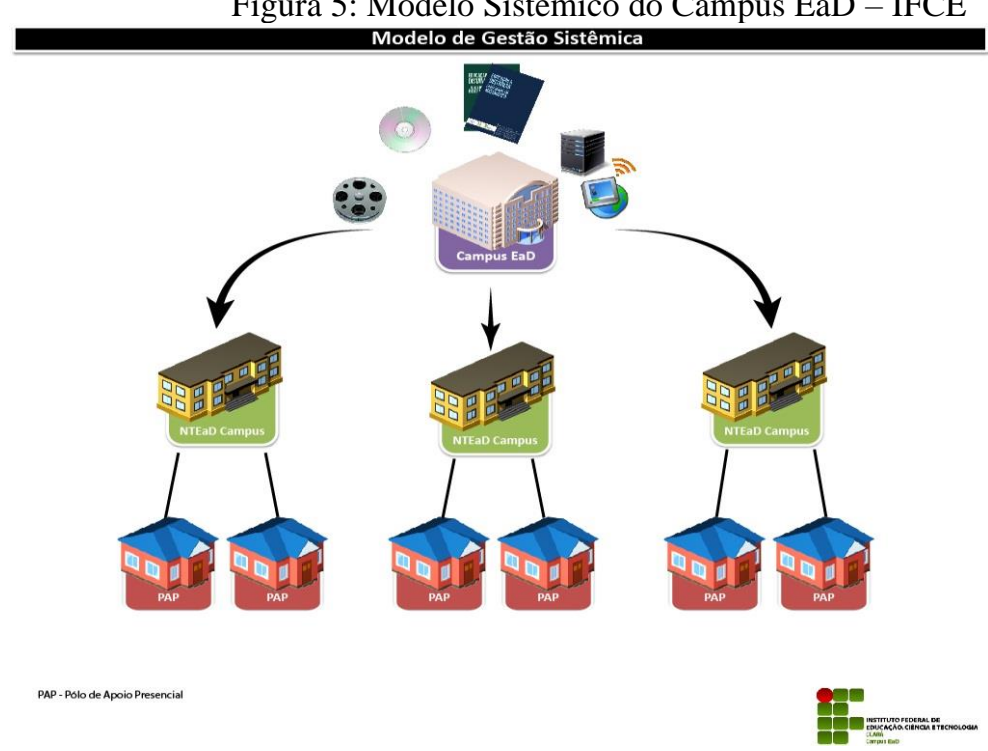

\section{Considerações finais}

Fonte: DEaD/IFCE (2012)

\footnotetext{
${ }^{8} \mathrm{https}: / /$ ifce.edu.br/acesso-rapido/campi/campi
} 
Como se pode perceber, pelo exposto, a Educação a Distância é uma modalidade de ensino que exige variadas especificidades nas ações, na infraestrutura, nas multidisciplinaridades, nas tecnologias, nas técnicas e na metodologia de ensino. Portanto, para que haja oferta de cursos a distância em uma instituição de ensino, há a necessidade de um olhar diferenciado, porém não como um apêndice ou modalidade pedagógica ordinária, mas de forma institucionalizada e consolidada. Os estudantes dessa modalidade são alunos regulares tal qual na modalidade presencial. Observe-se, ainda, que, na evolução da EAD no IFCE, descrita neste artigo, o Instituto vem acompanhando a evolução e dando suporte para ações passadas, presentes e futuras, haja vista que iniciamos nossas atividades inerentes à $\mathrm{EaD}$ na instituição como pesquisa, após um certo período foram instituídos Núcleos de Tecnologias, logo após da identificação do crescimento do número de alunos e cursos ofertados foi criada uma Diretoria Sistêmica.

Contamos um pouco dessa história nesse artigo, mostramos um pouco do cenário nacional existente, assinalamos as novas regulamentações da EAD, descrevemos um pouco da história da implantação e consolidação da EAD no IFCE e demos destaque ao desenho de uma sistêmica de gestão que precisou ser construída e foi construída ao longo do período de 2007 a 2015, de forma que alicerçava a migração da Diretoria de Educação a Distância-DEad para um campus virtual, pois, à época, já havia todos os processos e produtos construídos para essa institucionalização como unidade acadêmica. Ressalte-se aqui que ainda há uma resistência institucional do IFCE e a falta de tomada de decisão por parte de alguns dirigentes para se implementar o campus. Porém o projeto e o trabalho foram escritos e executados.

Os resultados desse trabalho se evidenciam nos credenciamentos e no reconhecimento dos cursos, nos casos de sucessos e boas práticas que podem ser reaproveitadas, adaptadas e replicadas, nos produtos gerados, nas pesquisas desenvolvidas e indicadas ao longo desse artigo, corroborando com o crescimento da EAD em níveis local e nacional.

Como a EAD institucional não foca apenas o ensino, mas engloba também a pesquisa e extensão, não se pode perder a riqueza e densidade dessa construção histórica e a experiência acumulada, além do capital humano preparado para dar continuidade ao percurso e à sedimentação na área de educação a distância institucional. 


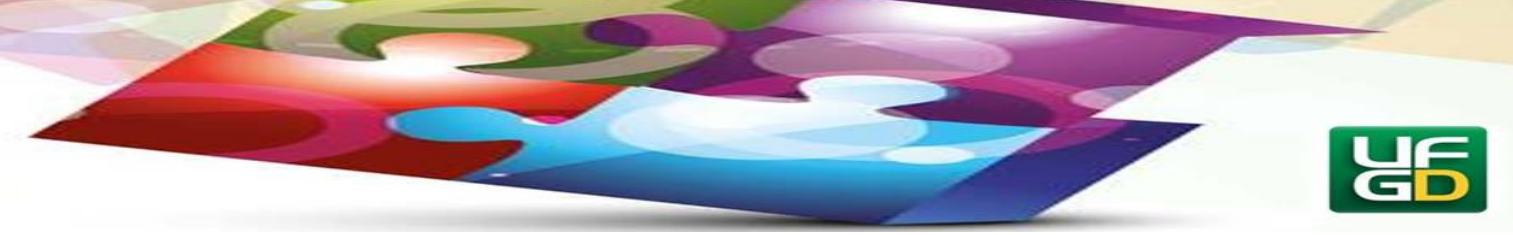

\section{Referências}

AMIEL, Tel; CRUZ DURAN, Maria Renata; COSTA, Celso José. Construindo Políticas de Abertura a partir dos Recursos Educacionais Abertos: Uma Análise do Sistema Universidade Aberta do Brasil. RELATEC: Revista Latinoamericana de Tecnología Educativa, v. 16, n. 2, p. 161-176, 2017.

ARANTES, Nélio. Sistemas de Gestão Empresarial: conceitos permanentes na administração de empresas válidas. 2. Ed. São Paulo: Atlas, 1998.

ARAÚJO, Breno Giovanni Silva. Modelo de gestão de cursos a distância no instituto federal de educação ciência e tecnologia - IFCE. 2014. 51 f. Monografia - Departamento de Administração da UFC, Universidade Federal do Ceará, 2014.

ARAÚJO, Ana Cláudia Uchôa. A feminização do magistério na educação a distância em perspectiva comparada: entre a professora tutora e a professora do passado. 2015. 226f. Tese (Doutorado) - Universidade Federal do Ceará, Programa de Pós-graduação em Educação Brasileira, Fortaleza (CE), 2015.

ARAÚJO, Régia Talina Silva et al. Modelagem de um sistema de gestão na Educação a Distância no Brasil utilizando redes de Petri Coloridas. Ingeniare. Revista chilena de ingeniería, v. 23, n. 1, p. 145-158, 2015.

BRAGA, Cristiane Borges. DidaTIC: um ambiente de produção de conteúdo didático digital para educação a distância. 2008. Dissertação (Mestrado Profissional em Computação Aplicada) - Universidade Estadual do Ceará, 2008.

BRASIL. Edital no 1, de 20 de dezembro de 2005. Chamada Pública para Seleção de Polos Municipais de Apoio Presencial e de Cursos Superiores de Instituições Federais de Ensino Superior a Distância para o Sistema UAB. Diário Oficial da União, Brasília, DF, 20 dez. 2005a.

BRASIL. Decreto 5.622, de 19 de dezembro de 2005. Regulamenta o artigo 80 da Lei no 9.394, de 20 de dezembro de 1996, que estabelece as diretrizes e bases da educação nacional. Diário Oficial da República Federativa do Brasil. Brasília, DF, 20 dez. 2005b. Disponível em: http://www.planalto.gov.br/ccivil_03/_Ato2004-2006/2005/Decreto/D5622.htm. Acesso em: 8 out. 2019.

BRASIL. Decreto $n^{\circ} 9.057$ de 25 de maio de 2017. Regulamenta o art. 80 da Lei $n^{\circ}$ 9.394, de 20 de dezembro de 1996, que estabelece as diretrizes e bases da educação nacional. Diário Oficial da União, 2017. Disponível em: < http://www.planalto.gov.br/ccivil_03/_Ato20152018/2017/Decreto/D9057.htm>. Acesso em: 06 de out. 2019.

BRASIL. Ministério da Educação. Portaria $n^{\circ}$ 4.059, de 10 de dezembro de 2004. Brasília, DF, $2004 . \quad$ Disponível em: $<$ http://portal.mec.gov.br/sesu/arquivos/pdf/nova/acs_portaria4059.pdf >. Acesso em: 08 out. 2019. 


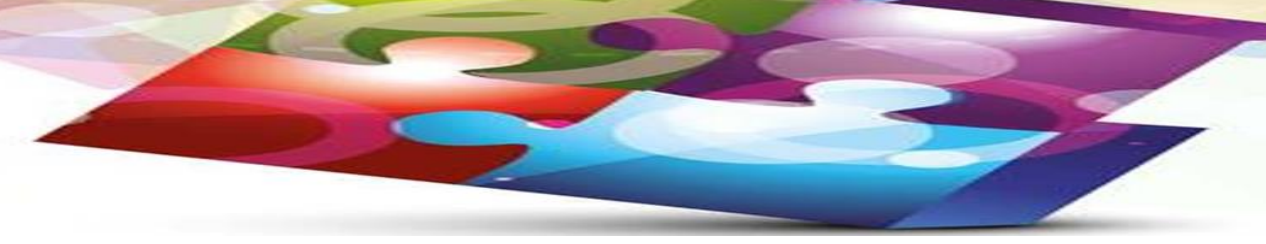

BRASIL. Ministério da Educação. Portaria $n^{\circ} 1.134$, de 10 de outubro de 2016. Brasília, DF, 2016. Disponível em: <https://abmes.org.br/arquivos/legislacoes/Port-MEC-1134-2016-1010.pdf>. Acesso em: 08 out. 2019.

BRASIL. Instituto Nacional de Estudos e Pesquisas Educacionais Anísio Teixeira - INEP. Censo da Educação Superior 2017 - Divulgação dos principais resultados. Brasília: Inep, 2018a. Disponível em: <http://portal.mec.gov.br/docman/setembro-2018-pdf/97041apresentac-a-o-censo-superior-u-ltimo/>. Acesso em: 06 de out. 2019.

BRASIL. Coordenação de Aperfeiçoamento de Pessoal de Nível Superior - CAPES. Relatório de Gestão do Exercício de 2017. Brasília, 2018b. Disponível em:

<https://uab.capes.gov.br/images/banners/18092018_Relat\%C3\%B3rio_de_Gest\%C3\%A3o_ CAPES_2017.pdf>. Acesso em: 06 de out. 2019.

FERREIRA, Marcello; CARNEIRO, Teresa Cristina Janes. A institucionalização da educação a distância no ensino superior público brasileiro: análise do Sistema Universidade Aberta do Brasil. Educação Unisinos, v. 19, n. 2, p. 228-242, 2015.

GOMES, Luiz Fernando. EAD no Brasil: perspectivas e desafios. Avaliação: Revista da Avaliação da Educação Superior, v. 18, n. 1, 2013.

GUEDES, Jane de Fontes. Produção de material didático para EaD nos cursos de licenciatura em matemática: o caso da UAB/IFCE. 2011. 126f. Dissertação (Mestrado em Educação) Universidade Federal do Ceará, Faculdade de Educação, Programa de Pós-graduação em Educação, Fortaleza-CE, 2011.

LE BOTERF, Guy; BARZUCCHETTI, Serge; VICENT, Francine. Comment manager la qualité de la formation. 2a. Ed. Paris : Les Editions d' Organisation, 1992.

MENEZES, Ebenezer Takuno de; SANTOS, Thais Helena dos. Verbete Programa de Expansão da Educação Profissional (PROEP). Dicionário Interativo da Educação Brasileira Educabrasil. São Paulo: Midiamix, 2001. Disponível em: <https://www.educabrasil.com.br/programa-de-expansao-da-educacao-profissional-proep/>. Acesso em: 06 de out. 2019.

MINEIRO, Hélvia Moreira. Formação do tutor: um estudo sobre os aspectos teóricos e práticos do curso de formação de tutores a distância do IFCE. 2011. 148 f. Dissertação (Mestrado em Educação) - Universidade Federal do Ceará. Faculdade de Educação, Programa de PósGraduação em Educação Brasileira, Fortaleza-CE, 2011.

MOREIRA, Marília Maia. Análise da visão do professor-tutor sobre a adequabilidade do material didático de matemática à luz da sequência Fedathi: o caso da licenciatura em matemática do IFCE. 2014. 146f. - Dissertação (Mestrado) - Universidade Federal do Ceará, Programa de Pós-graduação em Educação Brasileira, Fortaleza (CE), 2014.

OLIVEIRA, Antonio Mauro Barbosa et al. RE-Invente: Um Environnement Multimédia pour l'Enseignement Technique à Distance. In: Colloque Francophone de Gestion Réseau-GRES, Fortaleza. 2003.

OLIVEIRA, Antonio Mauro Barbosa et al. Big-Invente, towards an adaptive learning approach for distance education using data mining technologies and big data. Conexões-Ciência $e$ Tecnologia, v. 9, n. 1, 2015. 


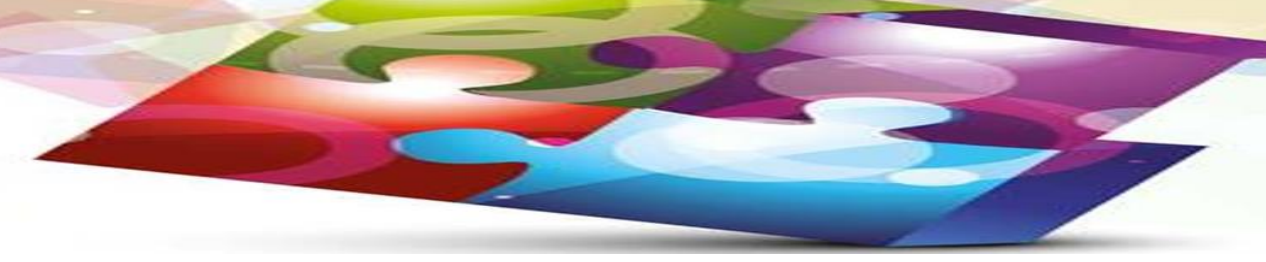

RODRIGUES, Luciana Andrade. Avaliação da usabilidade técnica e pedagógica da interface learning vectors: um estudo de caso no IFCE. 2015. 120 f. Dissertação (Mestrado Profissional em Computação Aplicada) - Universidade Estadual do Ceará, 2015.

SALES, Gilvandenys Leite. Learning Vectors $(L V)$ : um modelo de avaliação da aprendizagem em EaD online aplicando métricas não-lineares. 2010. 238 f. Tese (Doutorado em Engenharia de Teleinformática) - Centro de Tecnologia, Universidade Federal do Ceará, Fortaleza, 2010.

SANTOS, Andreine Lizandra. Direito à educação: a universidade aberta do brasil uma política pública de acesso ao ensino superior. In: XII Seminário Nacional Demandas Sociais e Políticas Públicas na Sociedade Contemporânea, 2016. Rio Grande do Sul: UNISC, 2016.

SOARES, José Marques. Um sistema de gestão para a educação tecnológica a distância, projeto e implementação. Dissertação (Mestrado) - Departamento de Computação da UFC, Universidade Federal do Ceará, 2001.

SANTIAGO, Lívia Maria de Lima. MADE: sistema de gestão e planejamento da matriz de design educacional de disciplinas a distância. 2014. 124 f. Dissertação (Mestrado Profissional em Computação Aplicada) - Universidade Estadual do Ceará, 2014.

SCHMIDLIN, Iraci de Oliveira Moraes. Presença em educação a distância: o caso dos cursos superiores da UAB/IFCE. 2013. 137f. - Dissertação (Mestrado) - Universidade Federal do Ceará, Programa de Pós-graduação em Educação Brasileira, Fortaleza (CE), 2013.

SERRA, Antônio Barros et al. EPT Virtual: espaço digital de apoio à pesquisa e aplicação das TICs na educação profissional e tecnológica. Revista Brasileira da Educação Profissional e Tecnológica, v. 1, n. 1, p. 118-130, 2008.

SILVA, Kleber do Nascimento. Avaltic: modelo de referência ergopedagógico para elaboração de instrumentos de avaliação em ambiente virtual. 2008. 222 f. Dissertação (Mestrado Profissional em Computação Aplicada) - Universidade Estadual do Ceará, 2008.

Data do envio do trabalho: 16/10/2019

Aprovado em: 30/11/2019

Publicado em: 18/12/2019 